IZA DP No. 7512

The Effect of Sorority Membership on

Eating Disorders and Body Mass Index

Susan Averett

Sabrina Terrizzi

Yang Wang

July 2013 


\title{
The Effect of Sorority Membership on Eating Disorders and Body Mass Index
}

\author{
Susan Averett \\ Lafayette College \\ and IZA
}

\section{Sabrina Terrizzi}

Moravian College

Yang Wang

Lafayette College

\author{
Discussion Paper No. 7512 \\ July 2013
}

IZA

P.O. Box 7240
53072 Bonn
Germany

Phone: +49-228-3894-0

Fax: +49-228-3894-180

E-mail: iza@iza.org

\begin{abstract}
Any opinions expressed here are those of the author(s) and not those of IZA. Research published in this series may include views on policy, but the institute itself takes no institutional policy positions. The IZA research network is committed to the IZA Guiding Principles of Research Integrity.

The Institute for the Study of Labor (IZA) in Bonn is a local and virtual international research center and a place of communication between science, politics and business. IZA is an independent nonprofit organization supported by Deutsche Post Foundation. The center is associated with the University of Bonn and offers a stimulating research environment through its international network, workshops and conferences, data service, project support, research visits and doctoral program. IZA engages in (i) original and internationally competitive research in all fields of labor economics, (ii) development of policy concepts, and (iii) dissemination of research results and concepts to the interested public.
\end{abstract}

IZA Discussion Papers often represent preliminary work and are circulated to encourage discussion. Citation of such a paper should account for its provisional character. A revised version may be available directly from the author. 
IZA Discussion Paper No. 7512

July 2013

\section{ABSTRACT}

\section{The Effect of Sorority Membership on Eating Disorders and Body Mass Index}

Eating disorders affect $12-25 \%$ of college women. Previous research established a positive correlation between sorority membership and eating disorders. We investigate a possible causal link between sororities and weight-related behaviors and eating disorders using data from the American College Health Association. Using Propensity Score Matching and Instrumental Variable methods, we confirm that sororities exert a negative effect on the weight-related behaviors of their members. However, females who are more resilient to these outcomes self-select into sororities, implying that females in sororities are less adversely affected by them than a female who was randomly selected to join a sorority would be.

JEL Classification: $\quad 112, I 18$

Keywords: obesity, underweight, BMI, sorority, anorexia, bulimia, eating disorders, weight control

Corresponding author:

Susan Averett

Department of Economics

Lafayette College

Easton, PA 18042

USA

E-mail: averetts@lafayette.edu

\footnotetext{
* The authors are grateful to D. Mark Anderson, Jason Hockenberry and participants at the 2012 meetings of the Southern Economic Association for helpful comments. All errors are our own.
} 


\section{Introduction}

Eating disorders (EDs) are prevalent in the United States. One in 200 women suffer from anorexia nervosa (AN), and two to three in 100 women suffer from bulimia nervosa (BN). These are two of the most common EDs (Patton, 1999; NIMH, 2002), and represent a growing concern to policymakers, medical professionals and families. Between 1999-2000 and 2005-2006, hospitalizations for EDs increased 18\% (Zhao and Encinosa, 2011), and these statistics only include those who have been diagnosed and hospitalized for EDs; there are still many that go undiagnosed: about only one in ten people with an ED is ever treated (Eating Disorder Statistics, 2003).

EDs are extremely detrimental to health. AN can lead to heart failure, low blood pressure, anemia, and kidney failure, and is the deadliest mental health illness (Sullivan, 1995; Hoste and La Grange, 2013). It can also prevent women from getting pregnant, as they can be too thin to menstruate. This is particularly relevant to college-aged women because they are at an age of which they are more likely to want to become pregnant currently or in the near future. Recovery rates for AN are quite low. In fact, $5-10 \%$ of anorexics die within ten years, 18 - 20\% die after 20 years, and only 30 - 40\% ever fully recover (Eating Disorder Statistics, 2003). Similarly, BN can lead to such health conditions as anemia, tooth erosion, torn throat, ulcers, dehydration, and heart failure. ${ }^{1}$

EDs are also costly. They are expensive to treat - averaging approximately $\$ 30,000$ a month for inpatient treatment, and most ED patients need at least three to six months of care (Eating Disorder Statistics, 2003). The total hospital costs for EDs increased 61\% from 1999-2000 to 2005-2006 (Zhao and Encinosa, 2011). In addition, 40\% of women with EDs have trouble at work, and 33\% often miss work entirely, equaling approximately 2.5 billion dollars in lost productivity; in 2001, AN, BN, and binge eating cost United States businesses over 3.8 billion dollars (PsychCentral, 2004). Moreover, there has not yet been an accurate measure of the monetary equivalence of the mental health costs to the women suffering from EDs and their families. Because of the severe

\footnotetext{
${ }^{1}$ womenshealth.gov (http://www.womenshealth.gov/body-image/eating-disorders/, last accessed on November 3rd, 2012).
} 
health consequences and the significant costs to women suffering from EDs, their families, the health care system, and the society as a whole, it is important to find the causes of EDs.

Research on the prevalence of EDs suggests an increased risk of developing an ED in a sorority setting. A recent article in the New York Times noted that many potential sorority members spend the summer before their freshman year exercising and dieting (Moore, 2012). A recent post on the popular website for women's health issues, ivillage, discussed whether sororities encourage EDs. ${ }^{2}$ Yet, as that post makes clear, sorority members may be predisposed to EDs or sororities themselves may serve as incubators for EDs and other negative weight-related behaviors. The purpose of this paper is to disentangle the selection effect from the causal effect of sororities on weight outcomes, weight-related behaviors, and disordered eating. Specifically, we apply Propensity Score Matching (PSM) and Instrumental Variable (IV) methods to data from the American College Health Association - National College Health Assessment II (ACHA-NCHA) survey to identify the possible causal effect of sorority membership on weight outcomes and disordered eating behaviors.

The remainder of the paper is organized as follows: we first review the literatures on EDs and the relationship between EDs and sorority membership; we then introduce our dataset which provides us with a rich set of controls; we follow with our econometric methods and the estimation results and the final section concludes.

\section{Literature Review}

In this section, we review literatures related to our research question from two perspectives. First, EDs, specifically AN and BN, are medical conditions. We therefore begin with a review of related medical literature, which provides an increased understanding of the possible determinants or confounding factors of EDs. We then review the related non-medical literature with a focus on the relationship between EDs

\footnotetext{
${ }^{2}$ http://www.ivillage.com/kappa-kappa-skinny-do-sororities-encourage-eating-disorders/4-a-122790. A comprehensive review of the literature on the relationship between eating disorders and sorority memberships is available in the Literature Review section.
} 
and sorority participation, where results from most of the studies are consistent with the general belief of the positive correlation between sorority and EDs. However, different studies have provided varied explanations for this correlation.

Although historical researchers reported evidence of AN and BN existing since ancient times (Bemporad, 1997), western societies only began to recognize these medical conditions in the 1960s and 1970s (Polivy and Herman, 2002). These two conditions are often considered within the same category of EDs, but they represent two distinct afflictions. AN is a "condition in which a person purposely limits his or her food intake, and refuses to maintain weight within a healthy range for his or her height and age” (Mitan, 2000 p. 276), while BN is categorized by "recurrent episodes of binge eating and compensatory behaviors to prevent weight gain, accompanied by an undue influence of body weight on self-esteem” (Mitan, 2000 p. 279). Mitan finds incidence rates of AN to be approximately $1 \%$ of females and $0.1 \%$ of males between the ages of 10 and 25 , while Polivy and Herman estimate these rates to be at a higher level between $3 \%$ and $10 \%$ of females aged 10 to 29. These diseases remain a significant mortality risk for the at-risk populations and despite increased attention and diagnoses, causes of these diseases are difficult to identify. Medical experts note the complexity in cause and treatment due to combinatorial effects across genetic and environmental factors (Mitan, 2000).

The genetic role explains $58 \%$ - $76 \%$ of variation in AN, and first-degree relatives of afflicted individuals remain at a twelve-fold increased risk of developing AN (Mitan, 2000). Researchers and medical experts also believe genes can explain some variation in BN, but none have been explicitly identified yet (Mitan, 2000).

In addition to the genetic component, the following factors are all identified to have some effect on the onset of these conditions: social pressure, personality traits, and family and environmental factors (Tozzi et al., 2003). Individuals diagnosed with AN and BN often cite underlying problems contributing to the onset of their disease. These problems range from high stress levels to sexual abuse and family dysfunction (Mitan, 2000; Polivy and Herman, 2000; Tozzi et al., 2003). Individual traits commonly associated with EDs 
include: perfectionism, low self-esteem, harm avoidance, and obsessive tendencies (Tozzi et al., 2003). In addition to individual personality traits, family dynamic appears to have a significant role in the onset of EDs. Common family interaction patterns among those afflicted include: rigidity, overprotectiveness, excessive control, and marital discord (Pope and Hudson, 1989; Palmer, 1990).

Because of the relatively low incidence of EDs in comparison to the prevalence of these individual and familial traits, Polivy and Herman (2002) believe there must be some underlying vulnerability leading to the disease in otherwise similar people. They argue that a stressful life event combined with low self-esteem, depressed mood, or anxiety can increase the risk of developing an ED. Mitan (2002) supports this argument by identifying the commonality of dual-diagnosis of $\mathrm{BN}$ with major depressive disorder, obsessive-compulsive disorder (OCD), and substance abuse.

The correlation between sorority membership and weight-related behaviors has long been noted (Squire, 1983). Researchers in various fields have been investigating this correlation mainly by comparing young college women's eating attitudes and behaviors to their sorority membership (e.g., Kashubeck et al., 1997, Schulken et al., 1997, Alexander 1998, Hoerr et al., 2002, Allison et al., 2004). Indeed, the correlation has been so widely acknowledged that certain actions aimed at reducing EDs and other potentially problematic weight-related behaviors have been taken with sororities as a target group (e.g., Becker et al., 2005). However, whether these kinds of action, and the policies behind them, can be of any use depends on whether this correlation actually indicates a causal relationship.

Specifically, the relationship between sorority participation and EDs or other weightrelated behaviors could be describing a causal relationship because a sorority is a potentially important peer group for female college students. Various studies have found that one's peer social support could have a significant role in mediating the relationship between one's own weight and weight-related behaviors (Forney, 2012; Wal, 2012). Additionally, there exist strong correlations between one's own weight status and weight- 
related perceptions and behaviors and those of his/her peers (Halliday and Kwak, 2009; Yakusheva et al., 2011; Forste and Moore, 2012; Yang and Huang, 2012). ${ }^{3}$

However, results of many studies aiming to explain the observed correlation between sorority participation and EDs or other weight-related behaviors (as well as other behaviors) raise the question of whether this observed correlation indeed indicates a causal relationship (Crandall 1988; Kashubeck et al., 1997; Sacerdote 2001; Gilbert and Meyer 2004; Basow et al., 2007; Forney et al., 2012). The relationship could be otherwise caused by a third variable leading to both sorority participation and the development of an ED or other weight-related behaviors.

\section{Data}

The data we use are from the fall 2008, spring 2009, and fall 2009 waves of the ACHANCHA survey. This survey includes 144,675 students from 123 colleges in three semesters in the United States. This dataset is particularly suitable for our project because it contains a large amount of information on college students' health and weight-related attitudes, perceptions, and behaviors.

It is worth noting that the schools that participate in the survey self-select themselves into the survey, so our results might be difficult to generalize to all schools and students due to the possible non-representativeness of the sample. Because the participating schools remain anonymous, the relative degree of representativeness cannot be directly tested. However, we do know that only schools that randomly selected students for the survey, or surveyed students in randomly selected classrooms, are included in the dataset. In addition, the generalizability of the ACHA-NCHA data has been evaluated by comparing it to other nationally representative surveys of the same population. ${ }^{4}$

\footnotetext{
${ }^{3}$ Various studies have found that sorority participation, or more generally membership in a Greek organization, is related to other aspects of college students' behaviors and development with mixed results (e.g., Alva 1998, Pike 2000, Grubb 2006, DeSimone 2007, Park et al., 2008).

${ }^{4}$ For more details on the validity tests, as well as information on other waves of this dataset, see http://www.acha-ncha.org/grvanalysis.html (last accessed on 10/28/2012).
} 
For the purpose of our study and considering the huge difference in the incidence rates between women and men, we focus only on female students. We have three sets of dependent variables: measurable weight outcomes (underweight $(\mathrm{BMI}<18)$, obese (BMI $\geq 30$ ), and $\mathrm{BMI}^{5}$ ), behaviors that influence health outcomes (dieting, trying to lose weight, vomiting or using laxatives to lose weight, and using pills to lose weight), and diagnosed medical conditions ( $\mathrm{AN}$ and $\mathrm{BN}$ ). Including this large range of potential outcomes is important because if sorority membership has any causal effect on young college women's attitudes towards eating, then a change in their eating behavior is likely to be more evident than a change in their weight outcomes.

We also include an extensive set of control variables in our study, which is made possible by the unique feature of the dataset we use, namely, ACHA-NCHA consists of a vast amount of information on a significant number of college students across the country. This long list of variables is required by our econometric method, and is justified by the evidence on contributing factors for EDs as discussed in our Literature Review section. Specifically, we include information on each student's age, year in school, race and ethnicity, current living arrangement, student status (transfer or international), working status (full-time, part-time, or not working), health status (excellent/very good, good, or fair/poor), whether and how much she volunteers, health insurance status, sexual orientation, self-perceived weight status ${ }^{6}$, relationship status, exercise level, frequency of wearing a seatbelt, use of mental health services, OCD diagnosis, grades, smoking and drinking behaviors, depression index, school size, interview semester, and past life experience (had adverse life event, experienced sexual and/or physical assault).

\footnotetext{
${ }^{5} \mathrm{BMI}$ is calculated using the formula: Weight(kg)/Height ${ }^{2}$ (meters), where weight and height are both selfreported. BMI might not be the best measure for muscle mass or body fat particularly for men, but it is still one of the best and most commonly used measures (Cawley, 2004) and it is the only measure available in our dataset. Additionally, even though both weight and height are self-reported, research has shown that for this age group, they are fairly accurate (Kuczmarski et al., 2001).

${ }^{6}$ This variable equals one if they accurately perceive their own weight; i.e. if their perception of their weight (underweight, overweight, obese, recommended weight) equals the category that is indicated by their own BMI.
} 
We exclude any women with missing or implausible values for those important variables $^{7}$. We also limit our sample to traditional college students; i.e. those 22 years or younger who are full-time students. Our final sample consists of 59,340 female college students with 5,828 of them in a sorority at the time of interview. The final sample is summarized in Tables 1 (outcome variables) and 2 (covariates) by sorority membership.

In terms of outcome variables, sorority members have lower BMIs and are less likely to be obese or underweight. They are also more likely to have been diagnosed with AN or $\mathrm{BN}$, and are more likely to report that they are dieting, vomiting, and using laxatives and pills to lose weight. These patterns are consistent with common beliefs about sorority women. All of the differences are statistically significant except for being underweight.

When we look at the control variables, we see that sorority members are more likely to be in better health, to spend substantially more time volunteering, to live in a sorority house (of course) or off campus, to drink and/or smoke occasionally, to be A or B students, to be heterosexual, to meet exercise recommendations, and to have experienced sexual/physical assault. However, sorority members are less likely to work part-time or full-time, to live with parents, to smoke daily, to be black, to be in a relationship, to obtain health insurance through college or parents, to think of themselves as underweight or overweight, and to be in a college with less than 5,000 students; but they are not much different in terms of past adverse life events compared to their non-sorority counterparts.

\section{Econometric Methods}

Our goal is to ascertain the causal effect of sorority membership on a variety of outcomes related to weight. Because we have observational data and lack a credible natural experiment, we have to be particularly cognizant of unobservable variables that may bias our estimates. The ideal empirical method would be to randomly assign individuals to sorority membership, and subsequently measure their weight-related outcomes. In the absence of such an experiment, we must rely on other methods. If we depend solely on OLS, we risk having biased estimates of the effect of sorority membership on various

\footnotetext{
${ }^{7}$ In the appendix, we include a detailed description of our sample derivation process.
} 
outcomes related to weight from failing to include all the characteristics that affect both sorority membership and those outcomes. In addition, even if all of the correct control variables are included, the linear specification of OLS could be incorrect (Reynolds and DesJardins, 2009). Furthermore, if those who join sororities differ in unobserved ways from those who choose not to join such a group, between-group comparisons may reflect those differences rather than the effect of sorority membership per se. Given all of these considerations, in this paper we use OLS with a rich set of controls and school fixed effects along with PSM and IV to ascertain the possible causal effect of sorority membership on weight, weight-related behaviors and having been diagnosed with AN or BN. ${ }^{8}$ Below we briefly describe each method.

\section{PSM}

Using PSM, we effectively create a counterfactual for individuals in the treatment group (in a sorority) using individuals from the control group (not in a sorority) who are most similar in terms of these covariates. Specifically, each observation in the treatment group is matched with one or more observation(s) in the control group. Under certain assumptions, the average difference in outcomes can then be attributed to the treatment (Rosenbaum \& Rubin, 1983). The PSM method relies on the "conditional independence assumption": all factors related to receiving a treatment are observed and measured (Black and Smith, 2004). This method addresses "selection on observables" but does not fully deal with the selection problem because unobserved characteristics are likely to influence both sorority membership and body weight. We calculate the propensity score ( $\hat{P}(x)$ ) using a Logit model including a large number of covariates as suggested in the literature. ${ }^{9}$ Using this information, we can calculate the Average Treatment effect on the Treated (ATT) defined as:

$E\left(Y_{0} \mid S=1, \hat{P}(x)\right)-E\left(Y_{0} \mid S=0, \hat{P}(x)\right)$

where $S=1$ if the individual is in a sorority and $Y_{0}$ is the outcome under scrutiny.

\footnotetext{
${ }^{8} \mathrm{An}$ advantage of PSM is that the matching estimators are non-parametric. Another possible method would be to use individual level fixed effects. However, the individual level fixed-effects method is not feasible in our case since our data are not longitudinal.

${ }^{9}$ The list of covariates is presented in table 2 and discussed further in the results section.
} 
There are various methods that can be used to match individuals; each of these has advantages and disadvantages. Most importantly, within finite samples there is a tradeoff between bias and variance of the ATT estimates when using different matching methods (Reynolds and DesJardins, 2009). Following Anderson (2012) we use several different matching methods including nearest neighbor, $k$ - nearest neighbors, nearest neighbor within caliper, kernel, local linear regression, and radius ${ }^{10}$. As noted above, the PSM method only allows us to match on observables thus to assess the extent of selection on unobservables, we use the IV method.

\section{Instrumental Variables}

We begin with a simple linear model:

$$
Y_{i}=\beta_{0}+\beta_{1} S_{i}+\delta^{\prime} X+\phi C_{t}+\varepsilon_{i},
$$

where $\mathrm{Y}_{\mathrm{i}}$ is one of the weight-related outcomes described above, $\mathrm{S}=1$ if the individual is in a sorority, 0 if not. $\mathrm{X}$ is a matrix of individual background characteristics described earlier and $C_{t}$ is a vector of school fixed effects which captures time-invariant unobservables across the $t$ colleges and universities in the sample. The parameter of interest, $\beta_{1}$, measures the average relationship between sorority membership and our weight outcomes. Because of the potential endogeneity in this relationship, OLS estimates of $\beta_{1}$ could be biased and thus we turn to the method of IV.

The IV method estimates the average causal effect, $\beta_{1}$, by using instruments, $Z_{i}$, for $S_{i}$. These instruments must be highly correlated with $\mathrm{S}$ but related to $\mathrm{Y}$ only through their effect on S. The two instruments we use are internally generated and measured at the school level. ${ }^{11}$ They are the percent of male students at the $t^{\text {th }}$ college who have joined a fraternity and the ratio of sorority to fraternity membership on the $t^{\text {th }}$ campus. Both should be predictive of sorority membership but have no independent effect on the

\footnotetext{
${ }^{10}$ Reynolds and DesJardins (2009) have an extensive discussion of the various matching methods.

${ }^{11}$ It is not possible to append external school specific instruments to the ACHA-NCHA data for privacy reasons. The anonymous school identifiers allow us to control for school fixed effects but preclude the appending of additional school-specific or geographic data which might serve as instruments.
} 
individual-level outcomes used in our analysis once we have controlled for our rich set of covariates. We estimate equation (2) using first OLS and then IV methods.

\section{Results}

We assess the effect of sorority membership on measurable weight outcomes (underweight, obese, and BMI), behaviors that influence health outcomes (dieting, trying to lose weight, vomiting or using laxatives to lose weight, and using pills to lose weight), and diagnosed medical conditions ( $\mathrm{AN}$ and $\mathrm{BN}$ ). Because we cannot control for unobservable characteristics that may contribute to these outcomes or behaviors, we compare analyses across three OLS and seven PSM specifications in addition to an IV specification; further, we assess the effect of selection bias using methodology discussed in Altonji et al., (2005; 2008), Rejesus et al. (2011), and Reynolds (2012). We find that sorority membership affects the weight and weight-related behaviors of members. We additionally find evidence ofself-selection into sororities; our results imply that females who choose to join a sorority are less affected by that decision in terms of weight-related behaviors than females who were randomly selected to join a sorority.

Our OLS regression results are shown in Table 3. The first panel shows the marginal effect of sorority membership on our various outcome measures without using any control variables, while the second panel includes all control variables listed in Table 2. The third panel of Table 3 displays the marginal effects from our most robust OLS specification in which we include all control variables in addition to school fixed effects.

When considering the measurable weight outcomes, we find sorority membership has a negative and statistically significant effect on measures of obesity and BMI, but find no significant effect of sorority membership on being underweight except in the top panel of Table 3 where we have no controls. The OLS effects associated with obesity and BMI decrease with increased controls, but remain significant at the $1 \%$ level. These results indicate some selection bias as observable characteristics mitigate a portion of the effect of sorority membership on these weight outcomes. Focusing on the third panel with the 
most controls, our OLS analyses find sorority membership to decrease obesity by $9.6 \%$ (0.008 percentage points) and decrease BMI by $0.65 \%$ (0.153 BMI units). ${ }^{12}$

We further consider how sorority membership affects weight-related-health behaviors including: dieting, trying to lose weight, vomiting or use of laxatives, and use of pills to lose weight. In general the OLS regressions show sorority membership has a positive and significant effect on all of the aforementioned behaviors. As shown in Table 3, these effects decrease in magnitude when additional controls are added, but all remain significant. The largest effects are found with the behaviors of vomiting or use of laxatives and using pills to lose weight. Using our estimates from the most robust OLS specification, we find that sorority membership increases the likelihood of these behaviors by $41 \%$ ( 0.015 percentage points) and 35\% (0.014 percentage points), respectively. Sorority membership increases the probabilities of dieting and attempting to lose weight through other means, by approximately 9\% (0.037 percentage points) and 5\% ( 0.030 percentage points), respectively.

We believe there exists some level of selection into sororities; our OLS results support this claim as the marginal effect of sorority membership attenuates with increasing controls. We first assess the extent of selection using PSM techniques (described in the Econometric Method section) in which we match females in sororities to females not in sororities using their observable characteristics to determine the ATT, and then consider this endogeneity issue using IV method. Tables 4 and 5 contain the marginal effects from the PSM technique using the Kernel matching method ${ }^{13}$ and the estimation results from the IV method for the weight outcomes (Table 4) and the behavioral and medical outcomes (Table 5). We include the number of observations that were on common support for the PSM estimates, and we include the first stage F-statistic and the Sargan test of overidentification for the IV estimates. We also show the OLS results from the fully specified model to facilitate comparisons.

\footnotetext{
${ }^{12}$ The percentage change is calculated by dividing the coefficient by the sample mean for each outcome. For example, $9.6 \%=0.008 / 0.0832$ where 0.0832 is the proportion of our sample that is obese.

${ }^{13}$ Results from all seven specifications are included in the appendix Table 1.
} 
With respect to the measurable weight outcomes (Table 4), the PSM results confirm that there is no effect of sorority membership on the likelihood that a female is underweight. The PSM effects on BMI and obesity are, however, significant and larger in magnitude than the OLS coefficient. Sorority membership could account for as much as a $0.81 \%$ reduction in BMI (0.189 BMI unit reduction) and a 14.42\% decrease in obesity (1.2 percentage points).

In terms of our behavioral and medical outcomes shown in Table 5, we find sorority membership to significantly affect dieting, trying to lose weight, vomiting or use of laxatives, and using pills to lose weight. In all cases, these effects are larger in the PSM regressions as compared to the OLS results. As in the OLS regressions, the largest effect occurs with increased vomiting or use of laxatives and increased use of pills to lose weight; females randomly assigned to a sorority experience a 47\% (1.7 percentage points) increase in the probability of vomiting or using laxatives and a 43\% (1.7 percentage points) increase in the probability of using pills to lose weight. Dieting behavior increases by $16 \%$ (6.6 percentage points), while attempting to lose weight through other means increases by approximately 8\% (4.8 percentage points).

Despite relatively small marginal effects of sorority membership on the medical conditions of AN and BN in the OLS models, our PSM results identify a large influence of sorority membership on these two medical conditions. Females in sororities have a $43 \%$ (0.4 percentage points) increased probability of developing bulimia and a 39\% (0.5 percentage points) increased risk of developing $\mathrm{AN}$, as compared to observationally equivalent peers not in a sorority. These effects are smaller in magnitude only when compared to the behavioral outcomes of vomiting or using laxatives and using pills to lose weight.

As previously discussed, the PSM techniques only account for selection on observables; we still need to identify how these results might be influenced by unobservable factors, and what information is provided by comparing the OLS effects to the relatively larger PSM effects. To assess the extent of selection on unobservables, we use the IV method, 
and as noted above these results are also reported in Tables 4 and 5. Our first stage Fstatistic is 1044.81 indicating that our instruments are highly predictive of sorority membership (Cameron and Trivedi, 2005). Sargan tests of overidentification indicate that our instruments are not correlated with the error term with the exceptions of underweight, vomiting/laxatives and BN, thus the IV results for these outcomes must be viewed with caution.

Using the IV approach, we find sorority membership to decrease BMI by 3.75\% (0.882 BMI units) and to decrease obesity by 39\% (3.3 percentage points). Sorority membership has even larger effects on behaviors, and increases the probability that one will use pills to lose weight by $61 \%$ (2.41 percentage points), is dieting to lose weight by $39 \%$ (15.9 percentage points), and is trying to lose weight through other means by $11 \%$ (6.16 percentage points). We do not find a significant effect of sorority membership on the medical conditions of AN.

When comparing the difference in magnitude between the OLS and PSM results and the OLS and IV results, we almost always find our OLS results to be smaller than those found in either of the other two specifications (exceptions include BMI and vomiting/laxatives but only for the IV specification). One explanation is the self-selection that exists among females choosing to join sororities. According to the literature, compared to those with high self-esteem, females with low self-esteem are less likely to join a sorority (Chapman et al., 2008), but more likely to have an ED (Polivy and Herman, 2002). There is also evidence that those who are rejected during the sorority rush process have lower self-esteem (Schwartz, 2012). For those females self-selecting into a sorority (those likely with higher self-esteem), they find themselves in an environment with increased social pressure to be thin, which may result in an increased likelihood of EDs or negative weight-related behaviors (Kashubeck et al., 1997; Hoerr et al., 2002; Basow et al., 2007; Forney et al., 2012).

Given this link between sorority membership and self-esteem, it would be ideal to control for self-esteem in our models. Unfortunately, our data do not contain such a measure. 
However, the fact that the coefficients from our IV and PSM models are larger than the OLS coefficients is consistent with the hypothesized self-selection into sororities of females who are more resilient to these adverse weight-related-health behaviors. Because the females in sororities may have relatively higher self-esteem, they may be more resistant to the pressure in this kind of environment than those with lower self-esteem. Consequently, if females are randomly assigned into a sorority (as assumed by the PSM approach) we would expect to find a larger effect of sorority membership on the probability of having an ED or engaging in other negative weight-related behaviors.

Similarly, this self-selection into sororities can explain the downwardly biased OLS results (as compared to the IV results). If females selecting into a sorority have high selfesteem and are less likely to exhibit negative weight-related behaviors, we would expect a negative bias from these omitted variables, i.e. we would find smaller marginal effects from our OLS specifications as compared to our IV specifications.

In order to confirm our hypothesis of self-selection, we conduct additional tests to gain insight into the level of selection bias necessary to overturn our results, and whether this selection bias could indeed exist in our sample. Using methods proposed by Altonji et al. (2005, 2008), we first estimate the selection and outcome equations using a bivariate Probit model. ${ }^{14}$ Subsequently, we vary the level of selection on unobservable compared to observable factors to obtain the range of possible effects. Table 6 provides the marginal effects resulting from these specifications.

The first row in Table 6 presents the marginal effects under the assumption that the selection on observable characteristics equals the selection on unobservable characteristics. These results do not however provide any indication as to whether or not these sources of selection are actually equal in our sample. The marginal effects show that invoking this assumption overturns our previous results, as the coefficient on underweight becomes positive and the coefficients on the weight-related behaviors and medical conditions become negative and significant.

\footnotetext{
${ }^{14}$ Because this method only works for binary outcomes, we do not do this analysis for the BMI outcome.
} 
We further assess the extent of selection bias by varying our $\rho$ values (level of correlation between observables and unobservables) from -0.01 to 0.5 . When we constrain $\rho$ to equal 0 , the case in which there is assumed to be no selection on unobservables, we find, as expected, results similar to our OLS regressions. As we vary $\rho$ from -0.01 to -0.02 , we find the estimated effect of sorority membership on our outcome variables indeed increases in magnitude, as in the case of our PSM specification. This supports our hypothesis that there exists selection bias in our sample. On the contrary, as we increase $\rho$ to $0.01,0.1$ and subsequently 0.5 , our marginal effects decrease until the results are overturned; i.e. the coefficients are now negative in sign. This implies that a small amount of positive correlation between observable and unobservable characteristics will overturn our results.

Our IV results and our sensitivity analyses support our claim of selection into sororities. Sorority membership exerts a negative effect on the weight outcomes, weight-related behaviors, and the medically diagnosed illnesses assessed in this paper. However, for those females self-selecting into sororities, these effects would likely be smaller (as seen in OLS), as compared to females randomly assigned to sororities from the college-aged population.

\section{Conclusion}

EDs are increasingly more prevalent, extremely detrimental to health, and vastly costly to the society. In this paper, we focus on one potential cause of EDs - sorority membership, for a particularly vulnerable group - female college students, because of the high prevalence of EDs in this group and the vast amount of evidence on the positive correlation between sorority membership and EDs.

We use OLS, PSM and IV to deal with the potential endogeneity issue, namely, that there might be unobservable characteristics affecting both sorority membership and weight, behavioral and medical outcomes. We apply these methods to a rich data set with an extensive amount of information on a large sample of female college students, and 
employ a number of robustness checks. Our results show that sorority membership indeed affects the weight outcomes, and especially the eating behaviors, of sorority members in a negative way. Because we find selection into sororities, our results further imply that females who choose to join a sorority have decreased adverse health effects resulting from that decision than would females who were randomly selected to join a sorority.

These results have important implications for policy makers, parents and school administrators in that sorority membership is a cause and not simply a correlate of adverse weight-related-health behaviors, even though we find no effect of sorority membership on diagnosed EDs. The self-selection of females into sororities provides a protective mechanism in that the females who join sororities appear to be more resilient to these adverse weight-related behaviors. However, if sororities were less selective, we would expect to see worse adverse weight-related outcomes. 


\section{References}

1. Alexander, L. 1998. The prevalence of eating disorders and eating disordered behaviors in sororities. College Student Journal, 32, 66-75

2. Allison, K., and Park, C. 2004. A prospective study of disordered eating among sorority and nonsorority women. International Journal of Eating Disorders. Volume 35, Issue 3, 354-358.

3. Altonji, J., Elder, T. and Taber, C. 2005. Selection on observed and unobserved variables: Assessing the effectiveness of catholic schools. Journal of Political Economy, 113, 152-184.

4. Altonji, J., Elder, T. and Taber, C. 2008. Using selection on observed variables to assess bias from unobservables when evaluating Swan-Ganz catheterization. American Economic Review, 98, 345-350.

5. Alva, S. 1998. Self-reported alcohol use of college fraternity and sorority members. Journal of College Student Development, Vol 39(1), 3-10.

6. Anderson, D. 2012. The impact of HIV education on behavior among youths: A propensity score matching approach. Working Paper.

7. Basow, S., Foran, K., and Bookwala, J. 2007. Body Objectification, Social Pressure, and Disordered Eating Behavior in College Women: The Role of Sorority Membership. Psychology of Women Quarterly. 31(4): 394-400.

8. Becker, C., Smith, L., and Ciao, A. 2005. Reducing Eating Disorder Risk Factors in Sorority Members: A Randomized Trial. Behavior Therapy 36, 245-253.

9. Bemporad, J. 1997. Cultural and historical aspects of eating disorders. Therapies in Medicine, 18, 401-420.

10. Cawley, J. 2004. The Impact of Obesity on Wages. Journal of Human Resources, Vol. 39, No. 2 pp. 451-474).

11. Chapman, L., Hirt, J., and Spruill, N. 2008. The effects of sorority recruitment on self-esteem. Oracle: The Research Journal of the Association of Fraternity Advisors 3.2: 38-51.

12. Cameron, C., and Trivedi, P. Microeconometrics: Methods and Applications. Cambridge University Press, 2005. 
13. Crandall, C. 1988. Social contagion of binge eating. Journal of Personality and Social Psychology, Vol 55(4), 588-598.

14. DeSimone, J. 2007. Fraternity membership and binge drinking, Journal of Health Economics, Elsevier, vol. 26(5), 950-967.

15. Eating Disorder Statistics. 2003 Retraining Grant Program. http://www.state.sc.us/dmh/anorexia/statistics.html (accessed April 15, 2012).

16. Forney, K., Holland, L., and Keel, P. 2012. Influence of peer context on the relationship between body dissatisfaction and eating pathology in women and men. International Journal of Eating Disorders. doi: 10.1002/eat.22039.

17. Forste, R., and Moore, E. Adolescent obesity and life satisfaction: Perceptions of self, peers, family, and school. Economics \& Human Biology (2012).

18. Gilbert, N., and Meyer, C. 2004. Similarity in young women's eating attitudes: Self-selected versus artificially constructed groups. International Journal of Eating Disorders. 36(2):213-9

19. Grubb, F. 2006. Does Going Greek Impair Undergraduate Academic Performance? A Case Study. The American Journal of Economics and Sociology, Vol. 65, No. 5 (Nov., 2006), pp. 1085-1110

20. Halliday, T, and Kwak, S. Weight gain in adolescents and their peers. Economics \& Human Biology 7.2 (2009): 181-190.

21. Hoerr, S., Bokram, R., Lugo, B., Bivins, T., and Keast, D. 2002. Risk for disordered eating relates to both gender and ethnicity for college students. Journal of the American College of Nutrition, 21, 307-314.

22. Hoste, R., and Le Grange, D. Eating Disorders in Adolescence in Handbook of Adolescent Health Psychology. (2013): 495-506.

23. Kashubeck, S., Marchard-Martella, N., Neal, C., and Larsen, C. 1997. Sorority membership, campus pressures, and bulimic symptomatology in college women: A preliminary investigation. Journal of College Student Development, 38, 40-48.

24. Kuczmarski, M., Kuczmarski R., and Najjar, M. 2001. Effects of Age on Validity of Self-Reported Height, Weight, and Body Maxx Index: Findings from the Third National Health and Nutrition Examination Survey, 1988 - 1994. Journal of the American Dietetic Association. 101(1): 28 - 34. 
25. Mitan L. 2000. Eating Disorders. In Diagnostic and Statistical Manual of mental Disorders ( $4^{\text {th }}$ ed.). Washington, DC: American Psychiatric Association.

26. Moore, A. 2012. Prepping Students for Sorority Rush. New York Times. July 16. http://www.nytimes.com/2012/07/22/education/edlife/prepping-students-forsorority-rush.html?pagewanted=all.

27. NIMH: National Institute of Mental Health: Eating Disorders: Facts About Eating Disorders and the Search for Solutions. Pub No. 01-4901. Accessed Feb. 2002. http://www.nimh.nih.gov/publicat/nedspdisorder.cfm.

28. Palmer T. 1990. Anorexia nervosa, bulimia nervosa: Causal theories and treatment. Nurse Practicioner, 15, 12-21.

29. Park, A., Sher, K., Krull, and J. 2008. Risky drinking in college changes as fraternity/sorority affiliation changes: A person-environment perspective. Psychology of Addictive Behaviors, Vol 22(2), 219-229.

30. Patton, G., Coffey, C., Carlin, J, Wolfe, R., and Selzer, A. Onset of adolescent eating disorders: population based cohort study over 3 years. British Medical Journal 318, no. 7186 (1999): 765-768.

31. Pike G. 2000. The Influence of Fraternity or Sorority Membership on Students' College Experiences and Cognitive Development. Research in Higher Education, v41 n1 p117-39.

32. Polivy J., and Herman, C. 2002. Causes of Eating Disorders. Annual Review of Psychology, 53, 187-213.

33. Pope H., and Hudson, J. 1989. Are eating disorders associated with borderline personality disorders? A critical review. International Journal of Eating Disorders, 8, 1-9.

34. Psychcentral. Eating Disorders Cost Millions of Dollars for Many U.S. Businesses. http://psychcentral.com/blog/archives/2004/08/17/eating-disorderscost-millions-of-dollars-for-many-us-businesses/. Accessed June 17, 2013.

35. Rejesus, R. Palis, F. Rodriguez D. Lampayan, R. and Bouman, B. 2011. Impact of the alternate wetting and drying (AWD) water-saving irrigation technique: Evidence from rice producers in the Philippines. Food Policy, 36, 280-288. 
36. Reynolds, L., and DesJardins, S. 2009. The use of matching methods in higher education research: Answering whether attendance at a 2-year institution results in differences in educational attainment. In Higher education: Handbook of theory and research, 47-97.

37. Reynolds, L. 2012. Where to attend? Estimating the effects of beginning college at a two-year institution. Economics of Education Review 31: 345- 362.

38. Rosenbaum, P., and Rubin, D. (1983). The central role of the propensity score in observational studies for causal effects. Biometrika, 70(1), 41-55.

39. Sacerdote, B. 2001. Peer Effects With Random Assignment: Results For Dartmouth Roommates. Quarterly Journal of Economics, v116(2,May), 681-704.

40. Schulken E., Pinciaro P., Sawyer R., Jensen, J., and Hoban, M. 1997. Sorority women's body size perceptions and their weight-related attitudes and behaviors. Journal of American College Health, 46(2), 69-74.

41. Schwartz, E. (2012). Misery Loves Company: A Perpetuation of Body Dissatisfaction in Sorority Women. http://www.cehs.ohio.edu/centerspartnerships/centers/c4he/CHEWP_2_2012_ES.pdf. Accessed June 17, 2013.

42. Squire, S. 1983. The Slender Balance: Causes and Cures for Bulimia, Anorexia and the Weight-Gain/Weight-Loss Seesaw. New York: Pinnacle.

43. Sullivan, P. 1995. Mortality in Anorexia Nervosa. American Journal of Psychiatry, Vol. 152 (7), July 1995, p. 1073-1074,

44. Tozzi F., Sullivan, P., Fear, J., McKenzie, J., and Bulik, C. 2003. Causes and Recovery in Anorexia Nervosa: The Patient's Perspective. International Journal of Eating Disorders, 33, 143-154.

45. Wal, J. The relationship between body mass index and unhealthy weight control behaviors among adolescents: The role of family and peer social support. Economics \& Human Biology (2012).

46. Yakusheva, O., Kapinos, K., and Weiss, M. Peer effects and the Freshman 15: Evidence from a natural experiment. Economics \& Human Biology 9.2 (2011): 119-132.

47. Yang, M., and Huang. R. Asymmetric Association between Exposure to Obesity and Weight Gain among Adolescents. (2011). Eastern Economic Journal. 
48. Zhao, Y., and Encinosa, W. 2011. Hospitalizations for Eating Disorders from 1999 to 2006. Statistical Brief \#70. Healthcare Cost and Utilization Project (HCUP). January 2011. Agency for Healthcare Research and Quality, Rockville, MD. 


\section{Appendix}

\section{Sample Selection}

The data used in this study was gathered from the National College Health Assessment survey. This survey asks students in colleges across the country about their health related behaviors and perceptions. We have data from three semesters: fall 2008, spring 2009 and fall 2009. Initially there were 144,675 respondents. We dropped 53,344 males and then 1,087 women for whom we could not ascertain if they were in a sorority. We lost an additional 549 who did not reveal their age and 2,579 who did not report their height and weight, 1,102 who did not answer the self-assessed health question, 3,113 who did not answer all the questions necessary to create the depression index, 277 with missing smoking information, 467 with missing alcohol information, 644 who did not report if they had an eating disorder that had caused them academic problems, 149 who did not report where they lived, 303 who did not report if they were working, 578 who did not report if they volunteered or not, 1,066 who did not report whether or not they had received mental health services, 188 who did not report if they had OCD, 124 who were missing information on trying to lose weight, 400 on did not report if they were currently dieting, 223 who were missing information on vomit/laxatives, 293 missing information on whether or not they take diet pills, 40 who failed to report if the believe they are the "right weight", an additional 279 whose race could not be determined, 167 who were missing information on relationship status, 365 who did not provide information on if they were a transfer student or not and 5,369 who were older than 22 years. This leaves us with a final sample of 59,339 women who are full time students. In our sample, about $10.9 \%$ of the women report being a member of a sorority. This is only one percentage point more women than report sorority membership before we dropped those with missing variables $(9.95 \%)$ which is likely due in part to our age restriction (since most sorority members are girls of the traditional college age-18 to 22) and our restriction that our sample be comprised of full-time college students. The average age in our sample is 19.70 while the average age overall in the full sample was 19.77-the ACHA sample contained relatively few individuals above the age of 22 years. Perhaps most importantly, the average BMI in our sample is 23.41 as compared to 23.43 for all women; $8.48 \%$ of the full sample is obese, while our final sample has $8.32 \%$ being obese. 
Table 1: Sample Means of Dependent Variables by Sorority Membership

\begin{tabular}{llll} 
Variable & All girls & In a sorority & Not in a sorority \\
\hline BMI & 23.414 & 23.2004 & 23.4373 \\
& $(4.6112)$ & $(4.2076)$ & $(4.6525)$ \\
Underweight & .0629 & .0578 & .0635 \\
& $(.2429)$ & $(.2334)$ & $(.2439)$ \\
Obese & .0832 & .0676 & .0849 \\
& $(.2762)$ & $(.251)$ & $(.2788)$ \\
Last 12 months diagnosed/treated for bulimia & .0116 & .0158 & .0111 \\
& $(.107)$ & $(.1246)$ & $(.1049)$ \\
Last 12 months diagnosed/treated with anorexia & .0128 & .0178 & .0122 \\
& $(.1124)$ & $(.1324)$ & $(.11)$ \\
In the last 30 days: dieting to lose weight & .4099 & .4832 & .4019 \\
& $(.4918)$ & $(.4998)$ & $(.4903)$ \\
Trying to lose weight & .5713 & .6217 & .5658 \\
& $(.4949)$ & $(.485)$ & $(.4957)$ \\
In the last 30 days: Vomit/laxatives to lose weight & .0365 & .0538 & .0346 \\
& $(.1875)$ & $(.2257)$ & $(.1828)$ \\
In the last 30 days: Diet pills to lose weight & .0396 & .0561 & .0378 \\
& $(.195)$ & $(.2301)$ & $(.1907)$ \\
Observations & 59339 & 5832 & 53507 \\
\hline
\end{tabular}

Standard deviations in parentheses 
Table 2: Sample Means, Control Variables, By Sorority Membership

\begin{tabular}{|c|c|c|c|}
\hline Variable & All Women & In a sorority & $\begin{array}{l}\text { Not in a } \\
\text { sorority }\end{array}$ \\
\hline \multirow[t]{2}{*}{ Second year student } & .236 & .2623 & .2331 \\
\hline & $(.4246)$ & (.4399) & $(.4228)$ \\
\hline \multirow[t]{2}{*}{ Third year student } & .2233 & .2524 & .2201 \\
\hline & $(.4164)$ & $(.4344)$ & $(.4143)$ \\
\hline \multirow[t]{2}{*}{ Fourth year student } & .1761 & .2049 & .173 \\
\hline & (.3809) & $(.4037)$ & $(.3782)$ \\
\hline \multirow[t]{2}{*}{ Fifth or higher year student } & .0376 & .0425 & .0371 \\
\hline & (.1903) & $(.2018)$ & $(.189)$ \\
\hline \multirow[t]{2}{*}{ Perception=Reality } & .7716 & .7767 & .7711 \\
\hline & (.4198) & $(.4165)$ & $(.4202)$ \\
\hline \multirow[t]{2}{*}{ Experienced sexual/physical assault } & .2901 & .3097 & .288 \\
\hline & $(.4538)$ & $(.4624)$ & $(.4528)$ \\
\hline \multirow[t]{2}{*}{ Health is very good or excellent } & .5731 & .5924 & .571 \\
\hline & $(.4946)$ & $(.4914)$ & $(.4949)$ \\
\hline \multirow[t]{2}{*}{ Health is fair or poor } & .0785 & .0698 & .0795 \\
\hline & $(.269)$ & $(.2548)$ & $(.2705)$ \\
\hline \multirow[t]{2}{*}{ Has had adverse life event } & .7942 & .7927 & .7944 \\
\hline & $(.4043)$ & $(.4054)$ & $(.4042)$ \\
\hline \multirow[t]{2}{*}{ Volunteers part-time } & .3938 & .5902 & .3724 \\
\hline & $(.4886)$ & $(.4918)$ & $(.4834)$ \\
\hline \multirow[t]{2}{*}{ Volunteers full-time } & .0037 & .0039 & .0037 \\
\hline & $(.0608)$ & $(.0627)$ & $(.0606)$ \\
\hline \multirow[t]{2}{*}{ Works part-time } & .5179 & .5096 & .5188 \\
\hline & $(.4997)$ & $(.5)$ & $(.4996)$ \\
\hline \multirow[t]{2}{*}{ Works full-time } & .038 & .0238 & .0395 \\
\hline & $(.1912)$ & $(.1525)$ & $(.1948)$ \\
\hline \multirow[t]{2}{*}{ International student } & .0699 & .1029 & .0663 \\
\hline & $(.255)$ & $(.3038)$ & $(.2488)$ \\
\hline \multirow[t]{2}{*}{ Transfer student } & .1726 & .1915 & .1706 \\
\hline & $(.3779)$ & $(.3935)$ & $(.3761)$ \\
\hline \multirow[t]{2}{*}{ Lives on campus but not dorm } & .064 & .0629 & .0642 \\
\hline & $(.2448)$ & $(.2429)$ & $(.245)$ \\
\hline \multirow[t]{2}{*}{ Lives in sorority house } & .0134 & .1211 & .0017 \\
\hline & $(.115)$ & $(.3262)$ & $(.041)$ \\
\hline \multirow[t]{2}{*}{ Lives off campus } & .2748 & .3092 & .2711 \\
\hline & $(.4464)$ & $(.4622)$ & $(.4445)$ \\
\hline \multirow[t]{2}{*}{ Lives with parents } & .1338 & .061 & .1417 \\
\hline & $(.3404)$ & $(.2394)$ & $(.3487)$ \\
\hline \multirow[t]{2}{*}{ Other living situation } & .0181 & .0118 & .0188 \\
\hline & $(.1333)$ & $(.1081)$ & $(.1358)$ \\
\hline Drinks occasionally & .7812 & .8801 & .7704 \\
\hline
\end{tabular}


Drinks Daily

Occasional smoker

Smokes Daily

Black

Hispanic

Other race group

Grades unknown

A or B student

D or F student

Grades unknown

Has used college mental health services

Age

Always wears seatbelt

Never, rarely or sometimes wears seatbelt

Meets exercise recommendations

In a relationship

Health insurance through college

Health insurance but not college or parents

Does not have health insurance

Health Insurance status unknown

Heterosexual
$(.4134)$

.0031

(.0553)

.2602

(.4387)

.0332

(.1791)

.0512

(.2205)

.0498

(.2175)

.1728

(.3781)

.0311

(.1737)

.859

(.3481)

.0059

(.0766)

.0311

(.1737)

.864

(.3428)

19.7096

(1.3025)

.8062

(.3953)

.037

(.1887)

.4531

(.4978)

.4918

(.4999)

.0856

(.2798)

.0353

(.1845)

.043

(.2028)

.1042

(.3055)

.9364

(.244)
(.3248)

.0038

(.0613)

.3229

(.4676)

.0231

(.1504)

.0362

(.1868)

.0408

(.1979)

.1212

(.3264)

.0177

(.1317)

.8903

(.3126)

.0036

(.0599)

.0177

(.1317)

.8517

(.3554)

19.8882

(1.2411)

.8061

(.3954)

.0322

(.1766)

.4883

(.4999)

.4726

(.4993)

.0648

(.2462)

.0219

(.1465)

.0305

(.172)

.046

(.2094)

.97

(.1706)
(.4206)

.003

(.0546)

.2534

(.4349)

.0343

(.1819)

.0529

(.2238)

.0508

(.2195)

.1784

(.3829)

.0326

(.1776)

.8556

(.3515)

.0061

(.0782)

.0326

(.1776)

.8654

(.3413)

19.6901

(1.3076)

.8062

(.3952)

.0375

(.19)

.4493

(.4974)

.4939

(.5)

.0879

(.2831)

.0367

(.1881)

.0443

(.2058)

.1106

(.3136)

.9328

(.2504) 
Sexuality unknown

Thinks very overweight

Thinks very underweight

School has fewer than 2,500 students

School has between 2500 and 4,999 students

School has between 5000 and 9,999 students

School has between 10,000 and 19,999 students

Fall 2008

Spring 2009

Observations

$$
.0217
$$

(.1456)

.035

(.1838)

.0036

(.0598)

.1207

(.3258)

.1173

(.3218)

.2266

(.4186)

.2227

(.416)

.2046

(.4034)

.5722

(.4948)

59339
.0101

(.1001)

.0302

(.1711)

.0024

(.0489)

.0727

(.2597)

.0789

(.2696)

.2646

(.4411)

.2322

(.4223)

.1718

(.3772)

.6082

(.4882)

5832
.0229

(.1497)

.0355

(.1852)

.0037

(.0609)

.126

(.3318)

.1215

(.3267)

.2225

(.4159)

.2216

(.4154)

.2081

(.406)

.5683

(.4953)

53507

Standard deviations in parentheses 


\begin{tabular}{|c|c|c|c|c|c|c|c|c|c|}
\hline In a sorority & $-0.006^{*}$ & - & $-0.237 * *$ & $0.081 * * *$ & $0.056^{* * *}$ & $0.019 * * *$ & $0.018 * * *$ & $0.005^{* *}$ & $0.006 * * *$ \\
\hline Constant & $\begin{array}{c}(0.003) \\
0.064 * * * \\
(0.002)\end{array}$ & $\begin{array}{c}(0.005) \\
0.085^{* * *} \\
(0.004)\end{array}$ & $\begin{array}{c}(0.103) \\
23.437 * * * \\
(0.078)\end{array}$ & $\begin{array}{c}(0.008) \\
0.402^{* * *} \\
(0.005)\end{array}$ & $\begin{array}{c}(0.007) \\
0.566 * * * \\
(0.004)\end{array}$ & $\begin{array}{c}(0.003) \\
0.035^{* * *} \\
(0.001)\end{array}$ & $\begin{array}{c}(0.003) \\
0.038 * * * \\
(0.001)\end{array}$ & $\begin{array}{c}(0.002) \\
0.011^{* * * *} \\
(0.001)\end{array}$ & $\begin{array}{c}(0.002) \\
0.012 * * * \\
(0.001)\end{array}$ \\
\hline Observations & 59,339 & 59,339 & 59,339 & 59,339 & 59,339 & 59,339 & 59,339 & 59,339 & 59,339 \\
\hline R-squared & 0.000 & 0.000 & 0.000 & 0.002 & 0.001 & 0.001 & 0.001 & 0.000 & 0.000 \\
\hline
\end{tabular}

OLS full set of controls (see Table 2 for variables)

\begin{tabular}{lcccccccccc}
\hline \multirow{2}{*}{ In a sorority } & 0.004 & $-0.009^{* *}$ & $-0.201^{* * *}$ & $0.045^{* * *}$ & $0.032^{* * *}$ & $0.014^{* * *}$ & $0.015^{* * *}$ & $0.004^{*}$ & $0.005^{* *}$ \\
& $(0.003)$ & $(0.004)$ & $(0.077)$ & $(0.008)$ & $(0.007)$ & $(0.004)$ & $(0.003)$ & $(0.002)$ & $(0.002)$ \\
Constant & $0.109 * * *$ & $0.166^{* * *}$ & $23.709^{* * *}$ & $0.357 * * *$ & $0.645^{* * *}$ & 0.024 & -0.014 & 0.017 & $0.026^{*}$ \\
& $(0.032)$ & $(0.031)$ & $(0.519)$ & $(0.062)$ & $(0.063)$ & $(0.026)$ & $(0.028)$ & $(0.014)$ & $(0.014)$ \\
& & & & & & & & & \\
Observations & 59,259 & 59,259 & 59,259 & 59,259 & 59,259 & 59,259 & 59,259 & 59,259 & 59,259 \\
R-squared & 0.060 & 0.392 & 0.373 & 0.075 & 0.098 & 0.030 & 0.030 & 0.023 & 0.029 \\
\hline
\end{tabular}

OLS full set of controls plus school fixed effects

\begin{tabular}{lcccccccccc}
\hline & & & & & & & & & \\
In a sorority & 0.003 & $-0.008^{* *}$ & $-0.153^{* *}$ & $0.037^{* * *}$ & $0.030^{* * *}$ & $0.015^{* * *}$ & $0.014^{* * *}$ & 0.003 & $0.004^{* *}$ \\
& $(0.003)$ & $(0.003)$ & $(0.064)$ & $(0.008)$ & $(0.007)$ & $(0.004)$ & $(0.003)$ & $(0.002)$ & $(0.002)$ \\
Constant & $0.141^{* * *}$ & $0.111^{* * *}$ & $22.485^{* * *}$ & $0.282^{* * *}$ & $0.577^{* * *}$ & 0.019 & -0.037 & 0.013 & $0.029^{* *}$ \\
& $(0.034)$ & $(0.034)$ & $(0.554)$ & $(0.064)$ & $(0.064)$ & $(0.027)$ & $(0.030)$ & $(0.015)$ & $(0.015)$ \\
& & & & & & & & & \\
Observations & 59,259 & 59,259 & 59,259 & 59,259 & 59,259 & 59,259 & 59,259 & 59,259 & 59,259 \\
R-squared & 0.067 & 0.402 & 0.390 & 0.081 & 0.104 & 0.034 & 0.036 & 0.026 & 0.033 \\
\hline
\end{tabular}

Standard errors clustered at the school level in parentheses

*** $\mathrm{p}<0.01, * * \mathrm{p}<0.05, * \mathrm{p}<0.1$ 
Table 4: Comparison of OLS, PSM and IV Results for Weight Outcomes

\begin{tabular}{|c|c|c|c|c|}
\hline & & OLS & $\begin{array}{c}\text { PSM: } \\
\text { Kernel } \\
\text { Matching }\end{array}$ & IV \\
\hline 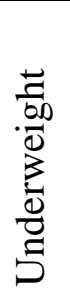 & $\begin{array}{l}\text { In a sorority } \\
\text { Sargan test of overid } \\
\text { F-test on } 1^{\text {st }} \text { stage } \\
\text { Observations } \\
\text { On common support }\end{array}$ & $\begin{array}{c}0.003 \\
(0.003) \\
59,259\end{array}$ & $\begin{array}{c}-0.002 \\
(0.003)\end{array}$ & $\begin{array}{c}0.018 \\
(0.014) \\
0.0031 \\
1044.81 \\
59,229\end{array}$ \\
\hline $\begin{array}{l}\mathscr{n} \\
\stackrel{\mathscr{U}}{0}\end{array}$ & $\begin{array}{l}\text { In a sorority } \\
\text { Sargan test of overid } \\
\text { F-test on } 1^{\text {st }} \text { stage } \\
\text { Observations } \\
\text { On common support }\end{array}$ & $\begin{array}{c}-0.008 * * \\
(0.003)\end{array}$ & $\begin{array}{c}-0.012 * * * \\
(0.004)\end{array}$ & $\begin{array}{c}-0.033^{* *} \\
(0.013) \\
0.4326 \\
1044.81 \\
59,229\end{array}$ \\
\hline$\sum_{m}^{B}$ & $\begin{array}{l}\text { In a sorority } \\
\text { Sargan test of overid } \\
\text { F-test on } 1^{\text {st }} \text { stage } \\
\text { Observations } \\
\text { On common support }\end{array}$ & $\begin{array}{c}-0.153 * * \\
(0.064)\end{array}$ & $\begin{array}{c}-0.189 * * * \\
(0.057)\end{array}$ & $\begin{array}{c}-0.088 * * * \\
(0.210) \\
0.3520 \\
1044.81 \\
59,229\end{array}$ \\
\hline
\end{tabular}

Standard errors clustered at the school level in parentheses $* * * \mathrm{p}<0.01, * * \mathrm{p}<0.05, * \mathrm{p}<0.1$ 
Table 5: Comparison of OLS, PSM and IV Results for Behavioral and Medical Outcomes

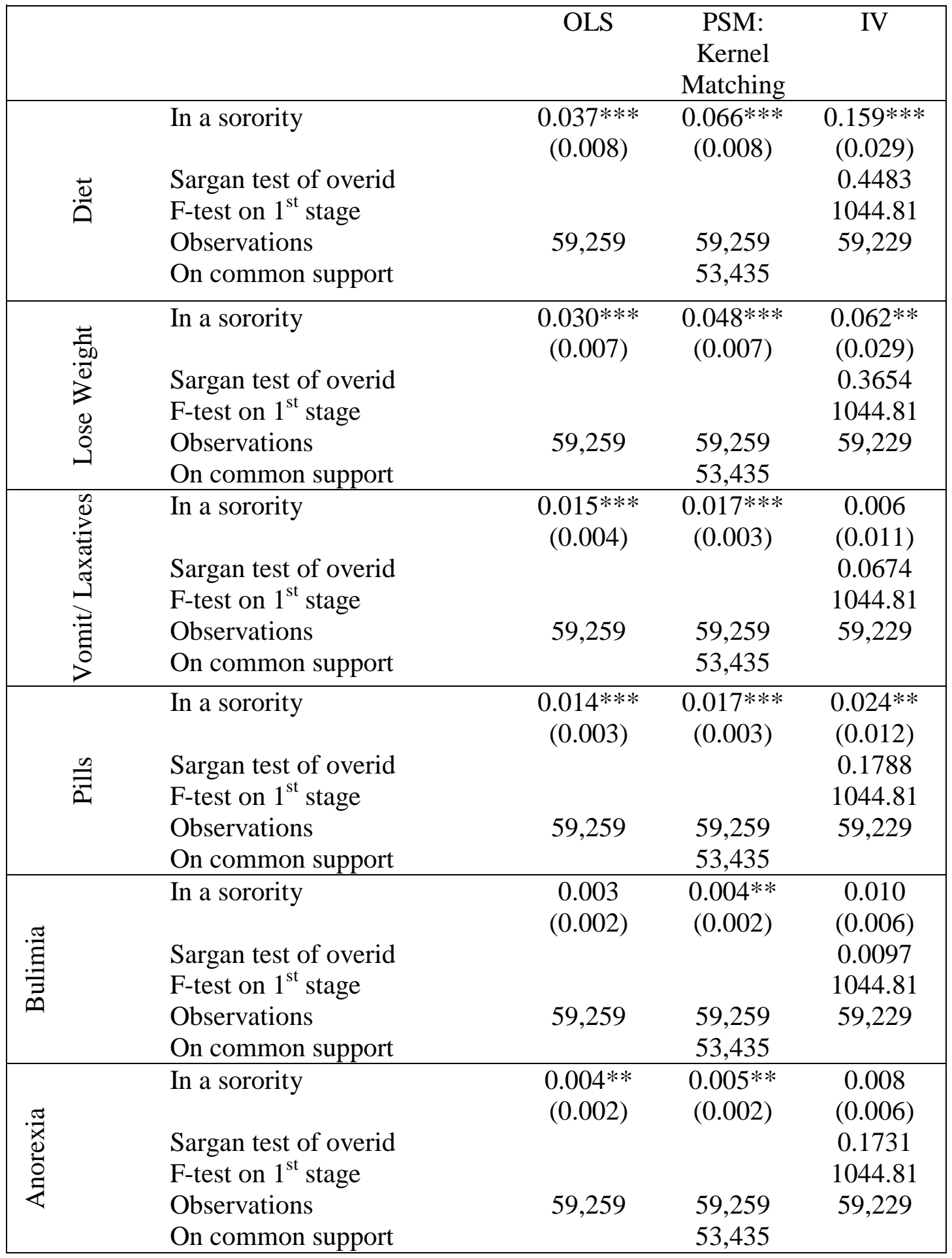

Standard errors clustered at the school level in parentheses

$$
\text { *** } \mathrm{p}<0.01,{ }^{* *} \mathrm{p}<0.05,{ }^{*} \mathrm{p}<0.1
$$


Underweight obese Vomit/laxative pills anorexia bulimia diet Lose weight

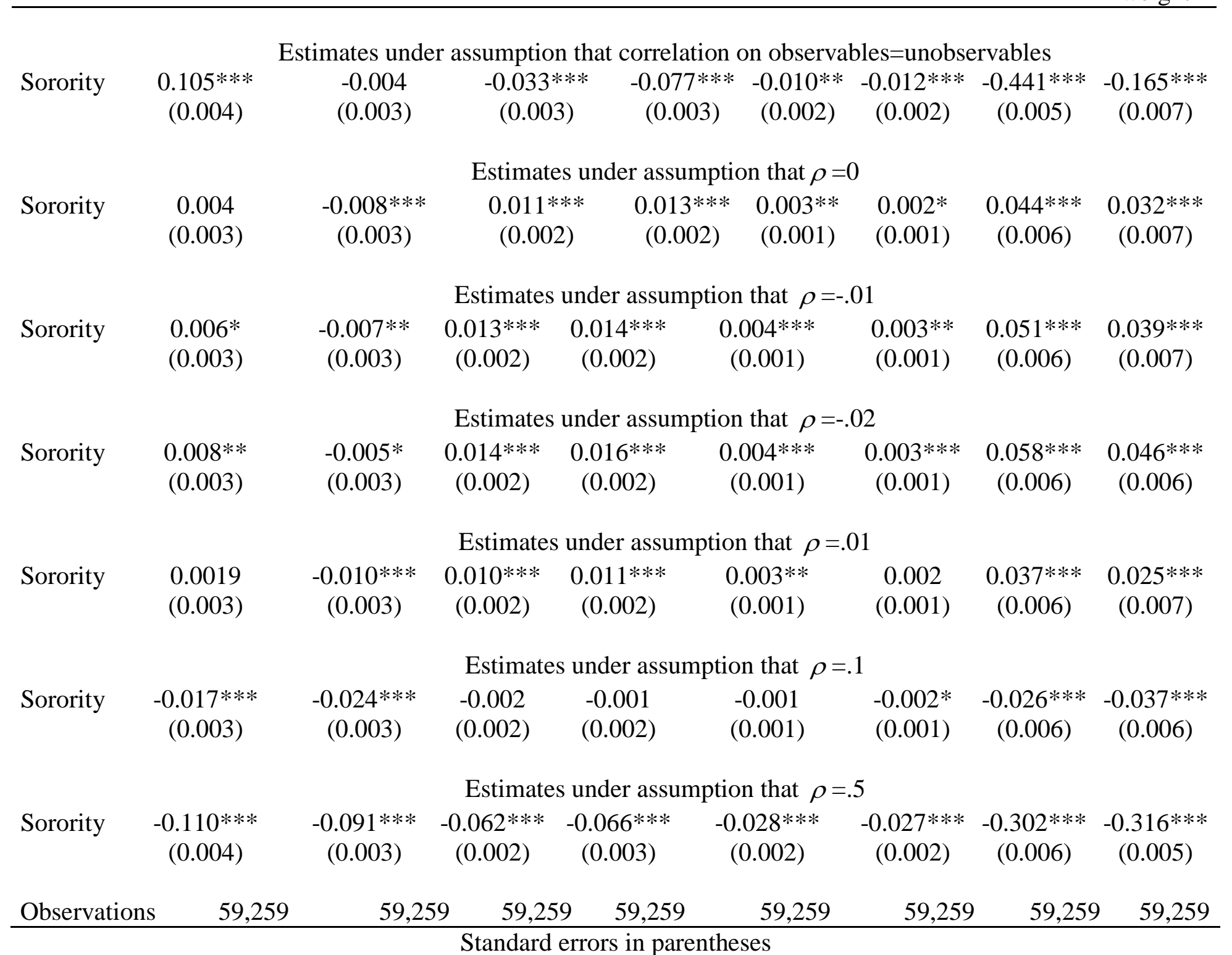


Appendix Table 1: Full Set of PSM Results

\begin{tabular}{lcccccccc}
\hline \multirow{2}{*}{ VARIABLES } & $(1)$ & $(2)$ & $(3)$ & $(4)$ & $(5)$ & $(6)$ & $(7)$ & $(8)$ \\
& $N N 1: 1$ & NN 3 & Caliper.001 & Caliper. & Caliper & LLR & radius & Kernel \\
\hline \multirow{3}{*}{ Underweight } & -0.002 & -0.003 & -0.002 & -0.001 & -0.001 & -0.001 & -0.000 & -0.002 \\
& $(0.005)$ & $(0.005)$ & $(0.005)$ & $(0.006)$ & $(0.006)$ & $(0.003)$ & $(0.003)$ & $(0.003)$ \\
Obese & -0.006 & -0.004 & -0.006 & -0.006 & -0.006 & $-0.011^{* * *}$ & $-0.011^{* * *}$ & $-0.012^{* * *}$ \\
& $(0.005)$ & $(0.005)$ & $(0.005)$ & $(0.006)$ & $(0.006)$ & $(0.004)$ & $(0.003)$ & $(0.004)$ \\
BMI & $-0.136^{*}$ & -0.046 & -0.136 & -0.134 & -0.135 & $-0.172^{* * *}$ & $-0.174^{* * *}$ & $-0.189^{* * *}$ \\
& $(0.072)$ & $(0.087)$ & $(0.095)$ & $(0.090)$ & $(0.116)$ & $(0.058)$ & $(0.063)$ & $(0.057)$ \\
Vomit/Lax & $0.018^{* * *}$ & $0.018^{* * *}$ & $0.017^{* * *}$ & $0.017^{* * *}$ & $0.017^{* * *}$ & $0.016^{* * *}$ & $0.016^{* * *}$ & $0.017^{* * *}$ \\
& $(0.004)$ & $(0.003)$ & $(0.004)$ & $(0.004)$ & $(0.005)$ & $(0.003)$ & $(0.004)$ & $(0.003)$ \\
Pills & $0.018^{* * *}$ & $0.018^{* * *}$ & $0.018^{* * *}$ & $0.018^{* * *}$ & $0.018^{* * *}$ & $0.016^{* * *}$ & $0.016^{* * *}$ & $0.017^{* * *}$ \\
& $(0.004)$ & $(0.004)$ & $(0.005)$ & $(0.004)$ & $(0.005)$ & $(0.003)$ & $(0.003)$ & $(0.003)$ \\
Anorexia & 0.001 & $0.004^{*}$ & 0.001 & 0.001 & 0.001 & $0.005^{* *}$ & $0.005^{* *}$ & $0.005^{* *}$ \\
Bulimia & $(0.003)$ & $(0.002)$ & $(0.003)$ & $(0.003)$ & $(0.003)$ & $(0.002)$ & $(0.002)$ & $(0.002)$ \\
& $0.004 *$ & $0.005^{* * *}$ & $0.004^{*}$ & 0.004 & 0.004 & $0.003^{*}$ & $0.004^{*}$ & $0.004^{* *}$ \\
Diet & $(0.002)$ & $(0.002)$ & $(0.002)$ & $(0.003)$ & $(0.002)$ & $(0.002)$ & $(0.002)$ & $(0.002)$ \\
& $0.064^{* * *}$ & $0.070^{* * *}$ & $0.063^{* * *}$ & $0.063^{* * *}$ & $0.063^{* * *}$ & $0.061^{* * *}$ & $0.061^{* * *}$ & $0.066^{* * *}$ \\
Lose Weight & $(0.011)$ & $(0.010)$ & $(0.014)$ & $(0.009)$ & $(0.012)$ & $(0.007)$ & $(0.008)$ & $(0.008)$ \\
& $0.059^{* * *}$ & $0.053^{* * *}$ & $0.058^{* * *}$ & $0.058^{* * *}$ & $0.058^{* * *}$ & $0.046^{* * *}$ & $0.045^{* * *}$ & $0.048^{* * *}$ \\
& $(0.012)$ & $(0.008)$ & $(0.011)$ & $(0.010)$ & $(0.011)$ & $(0.007)$ & $(0.008)$ & $(0.007)$ \\
Observations & 59,259 & 59,259 & 59,259 & 59,259 & 59,259 & 59,259 & 59,259 & 59,259 \\
\hline
\end{tabular}

Bootstrapped standard errors in parentheses (500 replications)

*** $\mathrm{p}<0.01,{ }^{* *} \mathrm{p}<0.05,{ }^{*} \mathrm{p}<0.1$ 
Appendix Table 2: Logit Regression to Obtain Propensity Score

VARIABLES

Age

Age squared

Health is very good or excellent

Health is fair or poor

Works full-time

Depression Index

Drinks occasionally

Drinks Daily

Occasional smoker

Smokes Daily

Black

Hispanic

Other race group

A or B student

D or F student

Diagnosed with OCD

Has used college mental health services

Always wears seatbelt

Never, rarely or sometimes wears seatbelt

Meets exercise recommendations

Constant in_sorority

$3.176^{* * *}$

$(0.364)$

$-0.078^{* * *}$

(0.009)

0.020

$(0.031)$

$-0.033$

(0.058)

$-0.585^{* * *}$

$(0.090)$

$-0.038 *$

$(0.019)$

$0.650^{* * *}$

$(0.045)$

$0.863 * * *$

$(0.236)$

$0.162 * * *$

(0.032)

$-0.394 * * *$

(0.093)

$-0.253^{* * *}$

(0.075)

$-0.241^{* * *}$

(0.070)

$-0.441^{* * *}$

(0.043)

$0.202^{* * *}$

(0.049)

$-0.204$

(0.232)

0.134

(0.093)

-0.069 *

(0.041)

$-0.028$

(0.038)

$-0.142 *$

(0.085)

$0.107 * * *$

(0.028)

(0.038)

$-34.589 * * *$

(3.616)

Observations

59,259

Standard errors in parentheses. ${ }^{* * *} \mathrm{p}<0.01,{ }^{* *} \mathrm{p}<0.05,{ }^{*} \mathrm{p}<0.1$. Model also controls for unknown GPA and size of school. 